\title{
АНТРОПОЛОГИЯ
}

\author{
Ю. Е. Березкин
}

\section{ДУША КОЩЕЯ. ВРЕМЯ И ПОСЛЕДОВАТЕЛЬНОСТЬ РАСПРОСТРАНЕНИЯ ФОЛЬКЛОРНЫХ МОТИВОВ, ОБЪЯСНЯЮЩИХ НЕУЯЗВИМОСТЬ ПЕРСОНАЖА 1}

\begin{abstract}
Фольклорные мотивы «внешней души» (персонаж умирает, когда уничтожены какой-то предмет или существо) и «ахиллесовой пяты» (уязвимое место персонажа находится на его теле, а не во внутренних органах) используются для объяснения смертности/бессмертия персонажа. Как и 2700 других, мировое распределение которых отражено в нашей электронной базе данных, эти мотивы являются не порождением универсального «первобытного сознания», а продуктом конкретных исторических процессов и обстоятельств. Цель статьи - определить эпоху и регион их первоначального распространения. Для этого сопоставлены материалы по Новому и Старому Свету. В Центральной и Южной Африке, в Австралии и Меланезии данные мотивы редки или вовсе отсутствуют, поэтому их появление уже в эпоху выхода-из-Африки невероятно. «Ахиллесова пята» обычна в текстах северо- и южноамериканских индейцев, включая огнеземельцев, тогда как ее евразийский ареал сильно разрежен. «Внешняя душа» популярна в пределах большей части Евразии, но в Америке встречается только к северу от Рио-Гранде. В последние тысячелетия на территории Старого Света мотив «ахиллесовой пяты» был, по-видимому, в основном вытеснен мотивом «внешней души», а в Америке сохранился благодаря ее изоляции от Евразии. Оба мотива были принесены в Новый Свет на ранних этапах его заселения. Их почти полное отсутствие в северо-восточной Азии и на северо-западе Северной Америки исключает позднюю диффузию через Берингов пролив. Соответственно возраст данных мотивов в Евразии должен превышать 15 тыс. лет, причем «ахиллесова пята», вероятно, древнее. Отсутствие или редкость этих мотивов в фольклоре народов северо-востока Сибири, где они должны были быть известны накануне их переноса в Новый Свет, согласуется с данными о значительных изменениях в генофонде населения Сибири в течение голоцена. Усложненный вариант «внешней души» с последовательным вложением животных и предметов, являющихся ее вместилищами, в Америке отсутствует. Он распространился лишь после античной эпохи в контексте волшебной сказки.
\end{abstract}

Ключевые слова: заселение Америки, древние мигращии, сравнительная фольклористика, мотив «внешней души», мотив «ахиллесовой пяты»».

\section{База данных мирового фольклора как инструмент для определения возраста мотивов}

Один из важнейших вопросов, на который призваны ответить исторические дисциплины, состоит в следующем: является ли эволюция культуры и социума универсальной или отдельные сообщества, между которыми отсутствует обмен информацией, могут развиваться по-разному? Тот же вопрос допустимо поставить иначе: развитие происходит в силу неких общих тенденций или (также) под влиянием случайных, т.е. действующих не повсеместно и побочных для соответствующих явлений, факторов?

\footnotetext{
${ }^{1}$ Статья написана при поддержке РНФ, проект № 18-18-00361. Благодарю А. Г. Козинцева за помощь в поисках литературы.
} 
Возможность второго варианта на протяжении не только XIX, но и XX в. всерьез не рассматривалась и ни одна антропологическая школа не пыталась ее проанализировать. На первый взгляд, кажется, что такую возможность должны были учитывать миграционисты, сосредоточившие внимание на ареальных различиях, а не на универсалиях. Но это не так. У миграционистов речь шла о комбинациях частных культурных особенностей в рамках стадиально однородных обществ, а не о макроистории. Э. Тайлор, Дж. Фрэзер или Л. Фробениус - все они смотрели на негров с берегов Касаи, даяков Борнео, алгонкинов Северной Каролины и тлинкитов Аляски как на одну пеструю совокупность первобытных племен. Данные по любой этнической группе сплошь и рядом репрезентировали их всех, причем исследователи имели в виду не только социальную организацию и хозяйство, но также фольклор и изобразительное искусство.

По сравнению с экономикой и социальной организацией фольклор и мифология просты для исследования. Их материал относительно однороден и относительно легко систематизируется. На нем удобно проследить закономерности, которые при обращении к другим сферам культуры требуют для анализа и осмысления несравненно больше усилий. В статье мы попытаемся продемонстрировать это на примере широко известных фольклорных мотивов. Задача состоит в том, чтобы показать, что эти мотивы, как и очень многое в культуре, не возникли повсеместно в результате прохождения обществом определенной стадии, а распространились в пределах определенных территорий в определенное время под действием конкретных и неповторимых исторических обстоятельств. Хотя эти обстоятельства вряд ли можно определить, сам факт региональной приуроченности явлений культуры, не имеющих значимой корреляции с природно-хозяйственными условиями, заставляет предполагать их наличие.

Первый из рассматриваемых мотивов - «внешняя душа», вместилище жизни персонажа вне его тела. Как и многие сюжеты и образы мирового фольклора, «внешняя душа» привлекла внимание Дж. Фрезера (Frazer, 1922. Ch. 67). Рассматривая в одном ряду актуальные верования, ритуальные практики и устные повествования, он стремился реконструировать представления, свойственные людям на ранней стадии развития культуры. Конечный источник таких представлений Фрезер, судя по всему, видел в общечеловеческой психике.

В наши дни «Золотая ветвь» имеет в основном историографический интерес. Тем не менее отраженные в книге взгляды, вполне оправданные для своего времени, но давно утратившие актуальность, не изжиты. Это можно сказать о концепции универсальной первобытной культуры - набору высказываний и практик, которые европейцам XIX в. казались противоречащими здравому смыслу и научным свидетельствам. Не исчезло и убеждение, что если культурная особенность функциональна (а как иначе?), то она возникла в контексте именно данной культуры, и задача исследователя - его раскрыть. То, что любая особенность может заимствоваться, эволюционисты во внимание не принимали. Даже пользуясь доступными в его время источниками, Фрезер легко мог заметить, что некоторые из рассмотренных им фактов культуры не распространены равномерно по миру - они зафиксированы на одних территориях и отсутствуют на других, причем эта дихотомия не совпадает с делением народов на «цивилизованных» и «первобытных». Но Фрезер жил в обществе, в котором господствовали другие идеи.

Обсуждать причины возникновения чего бы то ни было на основе одних только умозаключений - занятие неблагодарное. Если мы хотим выяснить, какие особенности фольклора и мифологии распространились в глубокой древности, а какие - в менее глубокой, следует использовать определенную методику анализа. 
Создание электронного каталога и цифровой базы данных мирового фольклора и мифологии позволило решить некоторые проблемы такого рода (Березкин, Дувакин б.г.; карты распространения мотивов онлайн, http://mapsofmyths.com, относительно режима доступа просьба обращаться к авторам). Поскольку наш текстовый каталог доступен в интернете (http://www.ruthenia.ru/folklore/berezkin), в статье ссылки на источники не приводятся. В каталоге они приведены в связи с текстами, содержащими мотивы L15A, L15D и L15H.

B основе нашего метода - выделение и картографирование повествовательных и образных единиц любой сложности, представленных в различных традициях. Определения таких единиц должны быть четкими и краткими. По мере поступления нового материала определения следует корректировать, но нельзя объединять варианты, которые похожи только частично, всех заявленных особенностей не содержат и ареально не совпадают, а именно это характерно для существующих указателей фольклорных сюжетов (Березкин, 2018: 67-68). Только при этом условии материал превращается в набор аналитических единиц, который можно обрабатывать точными методами.

Картографирование в глобальном масштабе позволило отделить те эпизоды и образы, которые распространены повсеместно или бессистемно, от регионально специфичных. Первые, может быть, и способны заинтересовать психологов, но для историков и антропологов важны только вторые. Сейчас нами прослежено мировое распределение почти 2700 тех эпизодов и образов, которые зафиксированы в пределах одних регионов и отсутствуют в других. Распространение редко (если вообще когда-либо) коррелирует с природными, социальными и хозяйственными факторами. Оно отражает совсем иное - конфигурацию сфер культурного взаимодействия, возникавших в разные эпохи, т.е. маршруты миграций и направления контактов. В отличие от элементов культуры, связанных со сферой жизнеобеспечения, содержание устных повествований мало влияет на жизнь людей. Именно поэтому наборы эпизодов и образов способны сохраняться при значительном изменении внешних условий и содержат данные о разных эпохах.

\section{Сопоставление данных по Евразии и Америке позволяет определить terminus ante quem распространения элементов фольклора}

Будь в нашем распоряжении одни лишь данные по Старому Свету, выявить хронологию и региональную приуроченность появления исследуемых элементов фольклора оказалось бы затруднительно. Поскольку опосредованные контакты между разными областями Евразии существовали всегда, то бывает сложно решить, имеем ли мы дело с заимствованиями или с параллельным развитием. Критически важной является возможность сравнивать данные по Евразии и Америке.

Время заселения Нового Света известно. Люди проникли туда 15/16-17 тыс. л.н., что подтверждается данными как археологии (Braje et al., 2017; Davis et al., 2019; Moreno et al., 2019; Wade, 2019; Waters et al., 2018), так и генетики (Wei et al., 2018). И если связь соответствующих американских и азиатских популяций оборвалась не позже 15 тыс. л.н., то в Старом Свете подобные мотивы должны были появиться еще раньше. Первые переселенцы в Америку, скорее всего, двигались вдоль тихоокеанского побережья, поскольку до 13 тыс. л.н. коридор Маккензи между Лаврентийским и Кордильерским ледниковыми щитами оставался закрытым или по крайней мере труднопроходим (Braje et al., 2017; Heintzman et al., 2016). По мере таяния ледников, блокировавших проход из Аляски в более южные области Нового Света, в этот про- 
цесс оказались втянуты континентальные популяции. Ряд археологов не согласен с данной гипотезой, опираясь на альтернативные датировки открытия коридора Маккензи - не позже 1415 тыс. л.н. (Potter et al., 2018). Однако следует подчеркнуть, что речь идет не о выборе между двумя потенциальными маршрутами миграции, а лишь об оценке их относительной важности.

Основная контроверза касается наличия или отсутствия среди самых ранних переселенцев тех, кто были генетически ближе к до- и немонголоидному населению Австралии, Меланезии и Юго-Восточной Азии, нежели к современным индейцам. Для Нового Света пока нет генетических данных того же возраста, что и древнейшие археологические находки, а останки голоценового времени «австролазийского следа» не содержат. В то же время он выявлен у современных обитателей Амазонии (Skoglund, 2015). Если прибрежный маршрут миграции стал доступен на пару тысячелетий раньше, чем внутриконтинентальный (сейчас эта гипотеза преобладает), то носители «австролазийского следа», скорее всего, воспользовались именно им. Но даже если оба маршрута проникновения из Берингии на юг стали доступны синхронно, береговая миграция открывала более прямой путь в Южную Америку, чем внутриконтинентальная. Так это или нет, но набор мотивов южноамериканской мифологии демонстрирует статистически надежные параллели с Меланезией (где лучше всего сохранилось наследие древних индо-тихоокеанских популяций), а набор мотивов североамериканской мифологии ближе сибирскому (Березкин, 2019).

Было бы опрометчиво напрямую сопоставлять материалы генетики и археологии с результатами, полученными на основе обработки данных фольклора. Мифологические образы и повествовательные эпизоды могут передаваться в процессе контактов между неродственными и даже разнокультурными популяциями при минимальном обмене людьми. Однако в этом случае ожидаема отражающая такую диффузию цепочка фиксаций, связывающая территории, в пределах которых происходили контакты. Такие цепочки, тянущиеся с северо-востока Азии в северо-западные районы Северной Америки, действительно прослеживаются (например, Васильев и др., 2005, рис. 6-43, 6-49, 52-57). Однако рассматриваемые сейчас материалы касаются мотивов, ареалы фиксации которых в Евразии и в Америке разделены тысячами километров. В этом случае предположение о переносе мотивов в процессе основного этапа заселения Нового Света, т.е. 15 тыс.

л.н. и в любом случае еще в плейстоцене, выглядит логичнее. И если соответствующие мотивы не возникли в Америке независимо, а попали туда из определенных областей Старого Света, то в Азии они тоже должны были распространиться еще в плейстоцене.

\section{Ареалы мотивов}

Для анализа выбраны три учтенных в нашем каталоге мотива. Два из них отражают представление о внешней душе, при уничтожении которой персонаж умирает. Первый (имеющий номер L15D) включает любые варианты, а второй (L15G) лишь такие, в которых речь идет о не менее, чем трех предметах и существах, помещенных одно в другое («в море дуб, в нем бык, в быке утка, в утке три яйца»). Этот мотив будем называть «последовательные вложения». Третий мотив (L15A) тоже связан с объяснением смертности или бессмертия персонажа. B этом случае уязвимый объект не удален от персонажа, однако находится он не в жизненно важных внутренних органах тела, а на периферии: в пятке, пальце и т.п.

Начнем с мотива L15A (рис. 1). Хотя в европейских языках «ахиллесова пята» превратилась в словесный штамп, в фольклоре Старого Света соответствующие свидетельства довольно редки. Из 550 выделенных традиций Евразии, Африки, Океании и Австралии образы 
типа «ахиллесовой пяты» зафиксированы лишь в 24-х, включая древнегреческий вариант. Большинство других записано в Евразии (от Швеции до Приморья и от Цейлона до северовостока Сибири), по одному - в Центральной Африке и Меланезии и два на северо-западе Австралии.

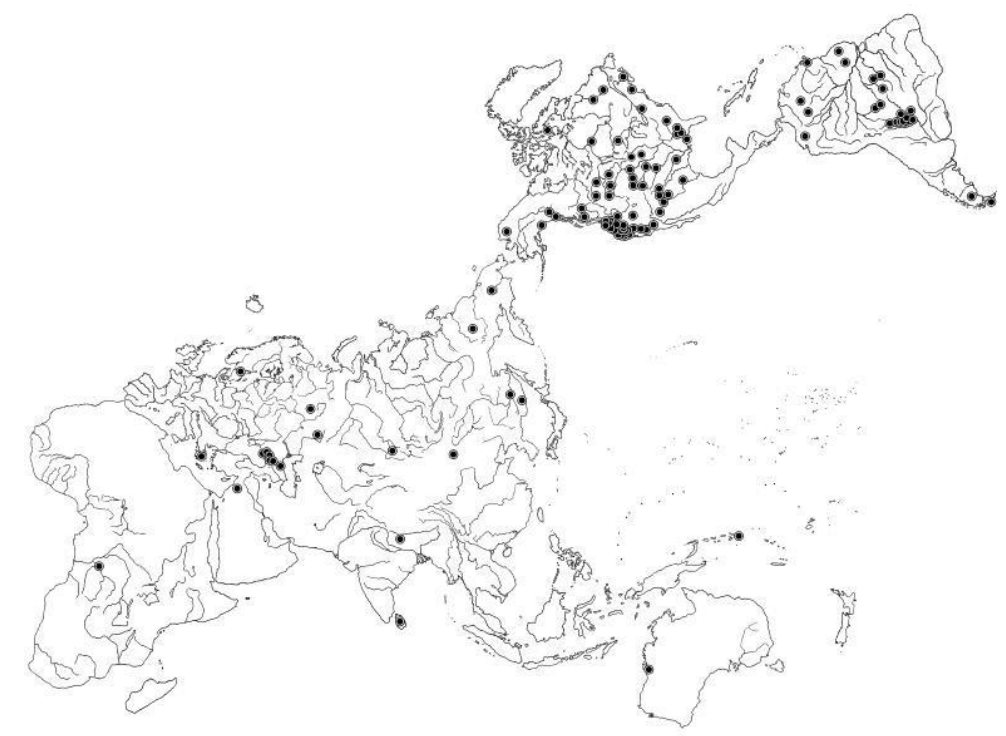

Рис. 1. Распространение мотива «Уязвимое место на теле» («ахиллесова пята» и сходные образы). Уязвимое место персонажа находится на поверхности тела, но не в жизненно важных внутренних органах

В Новом Свете картина иная. Из 412 выделенных традиций уязвимая пята, ноготь, колено и т.п. зафиксированы в 83-х - почти в пять раз чаще, чем в Старом Свете. Мотив был особенно популярен у индейцев Калифорнии и юга Колумбийского плато, но обычен и в других областях Северной Америки, за исключением западной Субарктики (из 18 атапасских традиций он есть лишь в двух - у тагиш и карьер). В Южной Америке мотив также обычен и зафиксирован вплоть до Патагонии (южные теуэльче) и Огненной Земли (яганы). В Центральной Америке и Мексике мотив отсутствует - как и в Восточной Азии. Это типичная ситуация: Южная Америка по набору мотивов статистически ближе к Меланезии и Индонезии, Мезоамерика - к Китаю, Северная Америка - к Сибири (Березкин, 2019).

Что касается «внешней души», то в пределах Старого Света данного мотива нет в Центральной и Южной Африке, а также в Австралии и на большей части островной Юго-Восточной Азии и Океании (рис. 2). Даже если не все публикации по фольклору этих областей обработаны, контраст с континентальной Юго-Восточной и особенно с Южной Азией, где мотив популярен, очевиден. Мотив не встречается в японском, корейском и китайском фольклоре. Единственное исключение - рассказ из книги китайского автора XVIII в. (Юань Мэй, 1977, № 125: 183-184). Зато «внешняя душа» обычна в сказках почти всех этнических традиций в пределах основной части Евразии и Северной Африки от Марокко и Норвегии до Таиланда и Сахалина. 


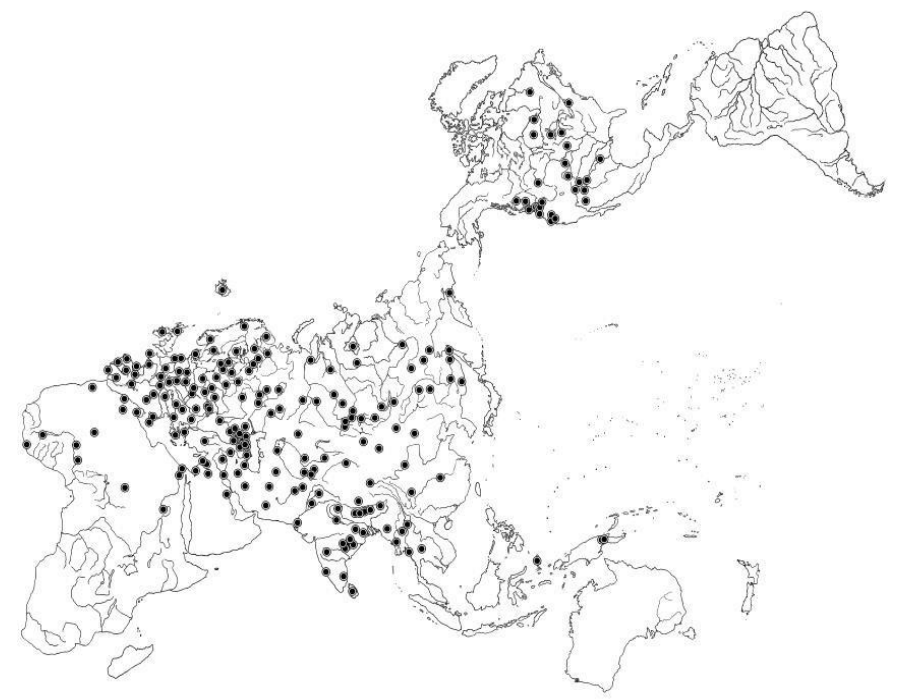

Рис. 2. Распространение мотива «Жизнь хранится вне тела» («внешняя душа»). Объект, в котором сосредоточена жизнь персонажа, отделен от него.

Персонаж умирает, когда уничтожена эта внешняя форма

В Северной Америке мотив известен примерно там же, где и «ахиллесова пята», т.е. от Лабрадора до Калифорнии и Юго-Запада. Однако он полностью отсутствует не только в Центральной, но и в Южной Америке. Он также не знаком ни атапаскам (и вообще на-дене), ни эскимосам.

Усложненный вариант «внешней души» с мотивом последовательных вложений (L15H) в Новом Свете отсутствует, а в Старом занимает более ограниченную территорию, чем «внешняя душа» в простом варианте (L15D). В частности, его нет в Индии (не считая одного пенджабского текста) и в Юго-Восточной Азии (рис. 3). Единственный случай в пределах северной Сибири - это долганы с их не только тюркской, но и русской компонентами в этногенезе.

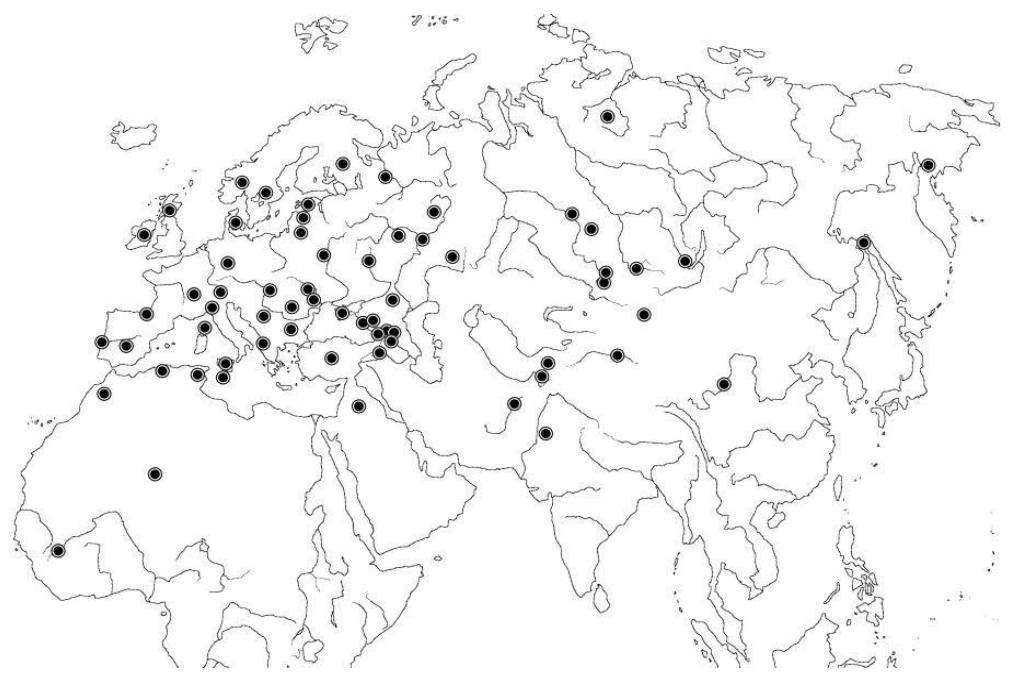

Рис. 3. Распространение мотива «Внешняя душа: последовательные вложения».

Объект, в котором сосредоточена жизнь персонажа, заключен в другом, тот в третьем и т.д. (типа яйцо в утке, утка в зайце, заяц в сундуке и т.п.). Либо животное, в котором заключена душа персонажа, превращается, убегая, в других животных. Описаны не менее трех вложений или превращений 


\section{Последовательность и время распространения мотивов}

Обширный, но разреженный ареал распространения «ахиллесовой пяты» в Старом Свете при множестве не только северо-, но и южноамериканских версий позволяет рассматривать этот мотив как реликт, в Евразии в основном вытесненный сходным - с точки зрения его роли в развитии сюжета - мотивом «внешней души». Обилие фиксаций в Новом Свете, включая крайний юг Южной Америки, означает, что данный мотив был принесен туда ранними мигрантами. Соответственно он должен был быть известен в Азии еще до начала заселения Нового Света. Для каких регионов Старого Света он был (наиболее) характерен 15-17 тыс. л.н., судить невозможно, поскольку не известно, какие именно популяции принесли его в Южную Америку. Отсутствие «ахиллесовой пяты» в Восточной и Юго-Восточной Азии при редкости в Австралии и Меланезии ставит под сомнение связь с «австралазийским следом», хотя речь и идет о ранних мигрантах.

Наличие в Северной Америке - причем не на Аляске, а в удаленных от Берингова пролива районах - мотива «внешней души»есть довод в пользу того, что и этот мотив проник в Новый Свет в эпоху основного этапа его заселения, в плейстоцене. Однако его отсутствие в Южной Америке предполагает несколько более позднее распространение, чем у «ахиллесовой пяты». Идет ли речь о столетиях или тысячелетиях, сказать сложно - возможно, эти мотивы были просто связаны с разными группами азиатских мигрантов, одна из которых достигла Южной Америки, а другая осталась в Северной. Все американские версии просты. В них нет и намека на «последовательные вложения». Говорится лишь о том, что жизнь (сердце) персонажа висит на стене жилища, хранится в корзине, в головном уборе и т.п.

Удревнять датировку распространения обоих рассматриваемых мотивов вплоть до эпохи начального расселения сапиенсов оснований нет. На это указывает отсутствие их в Африке южнее Сахары. Мотивы древнего африканского происхождения имеют отношение к объяснению смертности людей, но не отдельных персонажей, а человека как биологического существа (Березкин, 2013: 31-71; Berezkin, 2009).

Усложненный вариант «внешней души» с «последовательными вложениями», скорее всего, распространился недавно, уже после конца античной эпохи. Он встречается только в контексте волшебной сказки (особенно в сюжете 302; Uther 2004) и распространялся, видимо, вместе с ней. Этот мотив есть в «Тысяче и одной ночи», но отсутствует в древнегреческих источниках, где представлен лишь простой вариант (жизнь Мелеагра в недогоревшем полене). Ареал «последовательных вложений» тянется от Атлантики до Южной Сибири. Направление, в котором образ распространялся (с востока на запад либо с запада на восток) надежно определить нельзя. Однако поскольку на протяжении последних двух с половиной тысяч лет все миграции по Великой Степи шли с востока на запад, южносибирско-центральноазиатский центр появления мотива вероятнее европейского. Индия как мнимая «родина сказок» (Березкин, 2018) первоисточником наверняка не являлась, ибо в Южной Азии «последовательных вложений» попросту нет.

Следует обратить внимание на редкость как «ахиллесовой пяты», так и «внешней души» на Аляске, в американской Арктике и на северо-востоке Азии (единичные фиксации у эвенов, алюторцев и эскимосов). Все миграции в Новый Свет должны были проходить через Берингию. Соответственно при популярности обоих мотивов в глубинных областях Северной Америки распространение их в прошлом на Аляске и на северо-востоке Сибири сомнений не вызывает. Очевидно, что набор культурных особенностей, представленный на этих территориях, 
за прошедшие тысячелетия значительно изменился, что согласуется с данными генетиков, относительно значительных различий между древними и поздними популяциями сибирского северо-востока (Sikora et al., 2019).

\section{Выводы}

Картографирование фольклорных эпизодов и образов не только позволяет изучать динамику обмена информацией между обществами. Решая такую задачу, мы приближаемся и к установлению эпохальной стратиграфии фольклора - какие мотивы появились раньше, а какие позже и на каких именно территориях. Изложенные факты свидетельствуют в пользу того, что мотив «внешней души» появился в Евразии в конце плейстоцена. «Ахиллесова пята» (уязвимое место персонажа находится не в жизненно важных, а в периферийных органах) могла распространиться раньше либо эти мотивы имели разные очаги распространения. В эпоху выхода из Африки ни один из этих мотивов еще не был известен. Полное отсутствие или единичная фиксация обоих в пределах крупных регионов (Южная и Центральная Африка, Австралия и Океания, Бразильское нагорье, циркумполярная область) не позволяет оценивать данные мотивы как закономерно возникающие в любом «первобытном фольклоре».

Невозможно определить, какие именно и в какой мере представления и ощущения древних людей повлияли на содержание дошедших до нас устных повествований. Однако эпохальная датировка времени распространения образов и эпизодов возможна.

\section{Список литературы:}

Березкин Ю. Е. Африка, миграции, мифология. Ареалы распространения фольклорных мотивов в исторической перспективе. - СПб., 2013. - 319 с.

Березкин Ю. Е. Странствующая героиня и ее братья незамеченный сибирский сюжет // Томский журнал лингвистических и антропологических исследований. - 1918. - № 3(21). - С. 67-75.

Березкин Ю. Е. 2019. Последовательность переноса мифологических мотивов в Америку // Этнография. - СПб., 2019. - № 3(5). - С. 8-25.

Березкин Ю. Е., Дувакин Е. Н. Тематическая классификация и распределение фольклорно-мифологических мотивов по ареалам. Электронный аналитический каталог. Последнее обновление в декабре 2019. http://www.ruthenia.ru/folklore/berezkin

Васильев С. А., Березкин Ю. Е., Козинцев А. Г., Пейрос И. И., Слободин С. Б., Табарев А. В. Заселение человеком Нового Света: опыт комплексного исследования. - СПб., 2015. - 680 с.

Юань Мэй. Новые [записи] Ци Се (Синь Ци Се) или о чем не говорил Конфуций (Цзы бу юй). - М., 1977. - 501 C. Barbieri C., Barquera R., Arias L., Sandoval J.R., Acosta O., Zurita C., Aguilar-Campos A., Tito-Álvarez A.M., Serrano-Osuna R., Gray R., Mafessoni F., Heggarty P., Shimizu K.K., Fujita R., Stoneking M., Pugach I., FehrenSchmitz $L$. The Current Genomic Landscape of Western South America: Andes, Amazonia, and Pacific Coast // Molecular Biology and Evolution. - Oxford, 2019. URL: https://academic.oup.com/mbe/advance-article-abstract/doi/ 10.1093/ molbev/msz174/5539872.

Berezkin Yu. Why are People Mortal? World Mythology and the "Out-of-Africa" Scenario // Ancient Human Migrations. A Multidisciplinary Approach. - Salt Lake City, 2009. - P. 242-264.

Braje T. J., Dillehay T. D., Erlandson J. M., Klein R. G., Rick T. C. Finding the first Americans // Science. - 2017. - Vol. 358, iss. 6363. - P. 592-594.

Frazer J. G. The Golden Bough: a study in magic and religion. - New York, 1922. - 752 p.

Heintzman P. D., Froese D., Ives J. W., Soares A., Zazula G. D., Lette B., Andrews T. D., Driver J. C., Hall E., Hare P. G., Jass C. N., MacKay G., Southon J. R., Stiller M., Woywitka R., Suchard M. A., Shapiro B. Bison phylogeography constrains dispersal and viability of the Ice Free Corridor in western Canada // PNAS. - July 19, 2016. - Vol. 113, № 29. - P. 8057-8063. 
Moreno K., Bostelmann J. E., Macías C., Navarro-Harris X., De Pol-Holz R., Pino M. 2019. A late Pleistocene human footprint from the Pilauco archaeological site, Northern Patagonia, Chile // PlosOne. - April 24, 2019. - P. 1-16. URL: https://doi.org/10.1371/journal.pone.0213572.

Potter B. A., Beaudoin A. B., Vance Haynes C., Holliday V. T., Holmes C. E., Ives J. W., Kelly R. L., Llamas B., Malhi R., Miller S., Reich R., Reuther J. D., Schiffels S., Surovell T. A. Arrival routes of first Americans uncertain // Science. - 16 March, 2018. - Vol. 359, iss. 6381. - P. 1224-1225.

Sikora M., ... Willerslev E. \{50 авторов\}. The population history of northeastern Siberia since the Pleistocene // Nature. 2019. URL: https://doi.org/10.1038/s41586-019-1279-z.

Skoglund P., Mallick S., Bortolini M. C., Chennagiri N., Hünemeier T., Petzl-Erler M. L., Salzano F. M., Patterson N., Reich D. 2015. Genetic evidence for two founding populations of the Americas // Nature. - 2015. - 3 September. Vol. 525. - P. 104-109.

Uther H.-J. The Types of International Folktales. Part 1. - Helsinki, 2004. - 619 p.

Wade $L$. Relics of the first Americans? "Western Stemmed points" may be the signature of ancient migrants who spread south along the Pacific coast // Science. - 2017. - Vol. 356, iss. 6333. - P. 13-14.

Wade L. Ancient site in Idaho implies first Americans came by sea // Science. - 2019. - Vol. 365, iss. 6456. - P. 848-849. Wei L.-H., Wang L.-X., Wen S.Q., Yan S., Canada R., Gurianov V., Huang Y.-Z., Mallick S., Biondo A., O'Leary A., Wang C.C., Lu Y., Zhang C., Jin L., Xu S., Li H. Paternal origin of Paleo-Indians in Siberia: insights from Y-chromosome sequences // European Journal of Human Genetics. - Published online 10 July 2018. URL: https://doi.org/10.1038/s41431018-0211-6.

Waters M. R., Keene J. L., Forman S. L., Prewitt E. R., Carlson D. L., Wiederhold J. E. Pre-Clovis projectile points at the Debra L. Friedkin site, Texas Implications for the Late Pleistocene peopling of the Americas // Science. - 24 October, 2018. - Advances 4: eaat 4505.

Березкин Юрий Евгеньевич, доктор исторических наук, ведущий научный сотрудник.

Музей антропологии и этнографии им. Петра Великого (Кунсткамера) РАН.

Университетская наб., 3, Санкт-Петербург, Россия, 199034, berezkin1@gmail.com

Материал поступил в редакцию 5 ноября 2019 г.

\section{Yu. E. Berezkin}

\section{THE OGRE'S SOUL. AGE AND SEQUENCE OF THE SPREAD OF FOLKLORE MOTIFS THAT EXPLAIN THE INVULNERABILITY OF A PERSON}

The "external soul" (person dies when some object or creature is destroyed) and the "Achilles heel" (The only vulnerable spot is near the surface of person's body and not in his inner organs) are folklore motifs used to explain why a particular person cannot be killed or how he can be killed. As other 2700 motifs which global distribution is demonstrated in our database, the "external soul" and the "Achilles heel" are a product not of the universal "primitive mind" but of particular historical processes and circumstances and we try to reveal the age and region of their initial spread. In Central and South Africa, Australia and Melanesia both motifs are rare or totally absent. This makes improbable their origin in the Out-of-Africa time. The "Achilles heel" is often found in North and South America but its Eurasian area is sporadic. On the contrary, the "external soul" is very popular across most of Eurasia but in the New World it, is found only in North but not in South America. It looks plausible that in the Old World the motif of "Achilles heel" was mostly ousted by the "external soul" being preserved in the New World thanks to its isolation from Eurasia. The lack or rarity of these motifs in the Northeast Asia and in Alaska and American Arctic excludes, possibility of their late diffusion across Bering Strait. Because both motifs were brought to America by the early migrants, their age in Eurasia must exceed 15,000 years, the "Achilles heel" being probably older. At the time of the peopling of America, both motifs had to be well known to the oral traditions of the Northeast Asia. Their rarity or absence there in historic time is in 
conformity with significant differences between genetic samples of Early and Late Holocene populations of Siberia. The complicated version of the "external soul" according to which a life essence is hidden in a series of objects and beings, one inside the other, is absent in America. Such a variant probably spread across the Old World after the end of antiquity being used in fairytales.

Key words: peopling of America, early migrations, comparative folklore studies, the "external soul", the "Achilles heel".

\section{References:}

Barbieri C., Barquera R., Arias L., Sandoval J.R., Acosta O., Zurita C., Aguilar-Campos A., Tito-Álvarez A.M., Serrano-Osuna R., Gray R., Mafessoni F., Heggarty P., Shimizu K.K., Fujita R., Stoneking M., Pugach I., FehrenSchmitz L. The Current Genomic Landscape of Western South America: Andes, Amazonia, and Pacific Coast // Molecular Biology and Evolution. - Oxford, 2019. URL: https://academic.oup.com/mbe/advance-article-abstract/doi/ 10.1093/molbev/msz174/5539872

Berezkin Yu. Afrika, migratsii, mifologia. Areal'noe raspredelenie fol'klornyh motivov v istoricheskoi perspektive [Africa, Migrations, Mythology. Areal Patterns of the Folklore Motifs in the Historical Perspective]. - Saint Petersburg, 2013. - 319 p. (in Russian)

Berezkin Yu. Stranstvuyuschaya geroinya i ee brat'ya: nezamechenny sibirski syuzhet [Travelling Girl and Her Brothers: an Unnoticed Siberian Tale] // Tomski zhurnal lingvisticheskih i antropologicheskih issledovaniy [Tomsk Journal of Linguistic and Anthropology]. - Томск, 1918. - № 3(21). - P. 67-75. (in Russian)

Berezkin Yu. 2019. Posledovatel'nost' perenosa mifologicheskih motivov v Ameriku [The succession of the spread of mythological motifs into America] // Etnogfafia. - Saint Petersburg, 2019. - № 3(5). - P. 8-25. (in Russian)

Vasil'ev A. A., Berezkin Yu. E., Kozintsev A. G., Peiros I. I., Slobodin S. B., \& Tabarev A. V. Zaseleniye Chelovekom Novogo Sveta: Opyt Kompleksnogo Issledovaniya [Peopling of the New World: A Multidisciplinary Study]. - Saint Petersburg, 2015. - 680 p. (in Russian)

Berezkin Yu. Why are People Mortal? World Mythology and the "Out-of-Africa" Scenario // Ancient Human Migrations. A Multidisciplinary Approach. - Salt Lake City, 2009. - P. 242-264.

Berezkin, Yuri, and Evgeny Duvakin. Tematicheskaya klassifikatsiya i raspredeleniye fol'klorno-mifologicheskih motivov po arealam. Elektronny analiticheski katalog [The electronic analytical catalogue of folklore-mythological motifs: thematic classification and areal distribution]. Last updated December 2017. URL: http://www.ruthenia.ru/folklore/berezkin

Braje T. J., Dillehay T. D., Erlandson J. M., Klein R. G., Rick T. C. Finding the first Americans // Science. - 2017. - Vol. 358, iss. 6363. - P. 592-594.

Frazer J. G. The Golden Bough: a study in magic and religion. - New York, 1922. - 752 p.

Heintzman P. D., Froese D., Ives J. W., Soares A., Zazula G. D., Lette B., Andrews T. D., Driver J. C., Hall E., Hare P. G., Jass C. N., MacKay G., Southon J. R., Stiller M., Woywitka R., Suchard M. A., Shapiro B. Bison phylogeography constrains dispersal and viability of the Ice Free Corridor in western Canada // PNAS. - 2016. - July 19, - Vol. 113, № 29. - P. 8057-8063.

Moreno K., Bostelmann J. E., Macías C., Navarro-Harris X., De Pol-Holz R., Pino M. A late Pleistocene human footprint from the Pilauco archaeological site, Northern Patagonia, Chile // PlosOne. - April 24, 2019. - P. 1-16. URL: https://doi.org/10.1371/journal.pone.0213572.

Potter B.A., Beaudoin A.B., Vance Haynes C., Holliday V.T., Holmes C.E., Ives J.W., Kelly R.L., Llamas B., Malhi R., Miller S., Reich R., Reuther J.D., Schiffels S., Surovell T.A. Arrival routes of first Americans uncertain // Science. -16 March, 2018. - Vol. 359, iss. 6381. - P. 1224-1225.

Sikora M., ... Willerslev E. \{50 authors $\}$. The population history of northeastern Siberia since the Pleistocene // Nature. 2019. URL: https://doi.org/10.1038/s41586-019-1279-z

Skoglund P., Mallick S., Bortolini M. C., Chennagiri N., Hünemeier T., Petzl-Erler M. L., Salzano F. M., Patterson N., Reich D. 2015. Genetic evidence for two founding populations of the Americas // Nature. - 2015. - 3 September. Vol. 525. -P. 104-109.

Uther H.-J. The Types of International Folktales. Part 1. - Helsinki, 2004. - 619 p.

Wade $L$. Relics of the first Americans? "Western Stemmed points" may be the signature of ancient migrants who spread south along the Pacific coast // Science. - 2017. - Vol. 356. - Iss. 6333. - P. 13-14. 
Wade L. Ancient site in Idaho implies first Americans came by sea // Science. - 2019. - Vol. 365. - Iss. 6456. - P. 848849.

Wei L.-H., Wang L.-X., Wen S.Q., Yan S., Canada R., Gurianov V., Huang Y.-Z., Mallick S., Biondo A., O'Leary A., Wang C.C., Lu Y., Zhang C., Jin L., Xu S., Li H. Paternal origin of Paleo-Indians in Siberia: insights from Y-chromosome sequences // European Journal of Human Genetics. - Published online 10 July 2018. URL: https://doi.org/10.1038/s41431018-0211-6.

Waters M. R., Keene J. L., Forman S. L., Prewitt E. R., Carlson D. L., Wiederhold J. E. Pre-Clovis projectile points at the Debra L. Friedkin site, Texas-Implications for the Late Pleistocene peopling of the Americas // Science. - 24 October, 2018. - Advances 4: eaat4505.

Yuan Mei. Novye zapisi Tsi Se, ili O chem ne govoril Konfutsi [Censored by Confucius]. - M., 1977. - 501 p. (in Russian)

Berezkin Yuri Evgenievich, Doctor of Historical Sciences, Leading Researcher.

Museum of Anthropology and Ethnography Peter the Great (Kunstkamera) RAS.

Universitetskaya nab., 3, St. Petersburg, Russia, 199034.

E-mail: berezkin1@gmail.com 